\title{
Translator's Note
}

The source of most of the Johann Cornies correspondence, and of his other documents, is the Peter J. Braun Russian Mennonite Archive, housed in the State Archives of the Odessa Region in Ukraine. They were gleaned by checking the microfilm of the somewhat disorganized files of the first half of the Braun Archive and cover the years 1812 to 1848 , the period of Cornies' activity.

All of the German documents are in the German Gothic script that was in use at the time. Many were written in a careful, regular hand; others were obviously dashed off or written by someone with limited practice in writing. The documents themselves show many personal styles and personalities, and it is regrettable that these cannot be conveyed adequately without turning the translations into quaint documents.

Translation methods have been as direct as possible. The German umlaut has been translated using the conventional method of adding the letter ' $\mathrm{e}$ ' after the vowel with the umlaut. The spelling of German names has not been changed; Russian names have been spelled in the Library of Congress style of transliteration from Russian into English. The reference for the spelling of Mennonite village names is the map reproduced in Franz Issac's Die Molotschnaer Mennoniten. Names of organizations have been translated into English, for example, "Agricultural Society" for "Wirtschaftlicher Verein." Titles of German publications are given in German with the literal English translation following in brackets. Sometimes translations could not be found for individual terms - often either terms of local application, or terms transferred from Russian - and in these cases the translator has made an attempt to convey the sense of the sentence, sometimes including the term in the document in square brackets. 


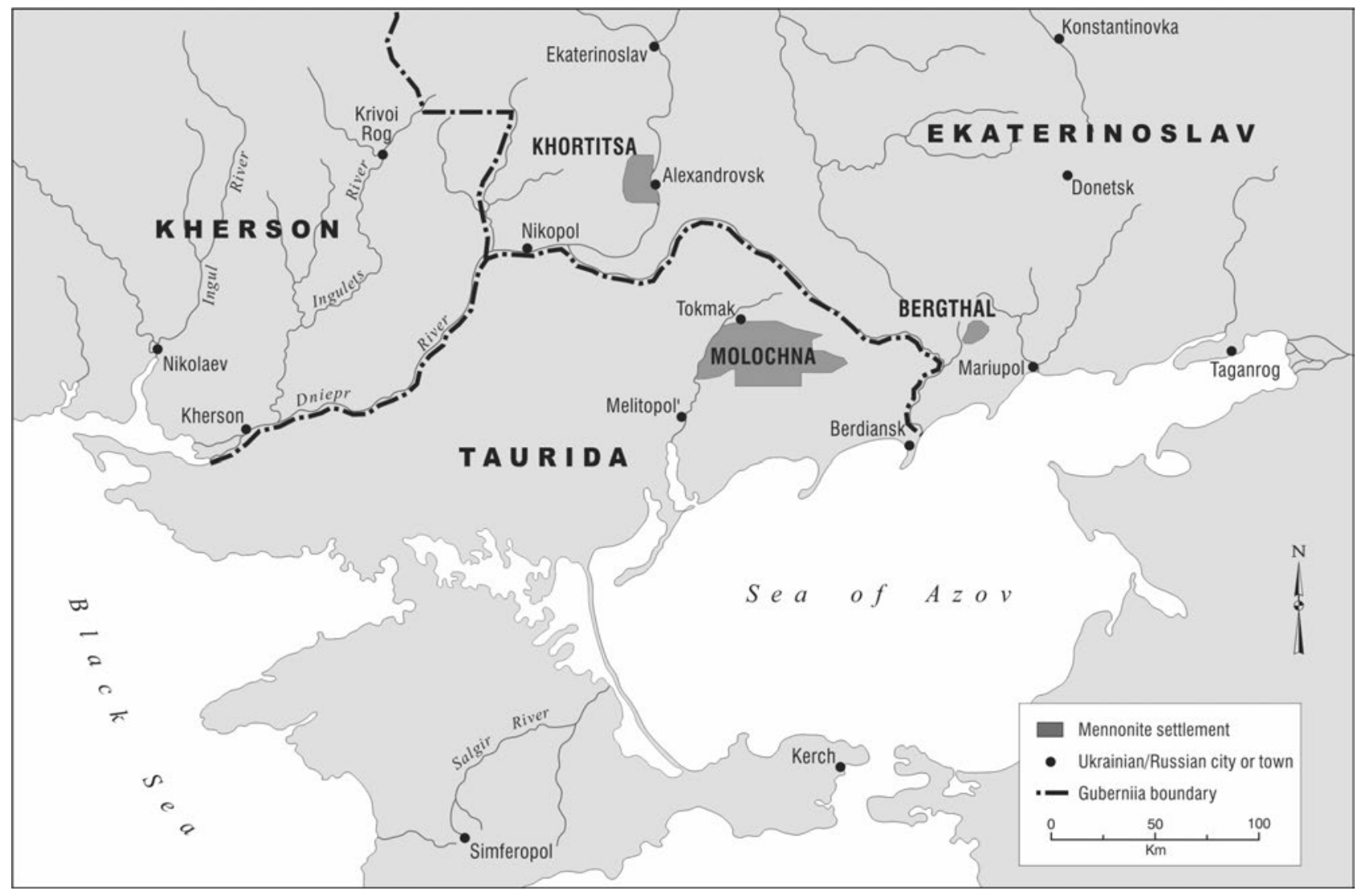

Map 1: Mennonite settlements in New Russia, circa 1880. Harvey L. Dyck, translator and editor, A Mennonite in Russia: The Diaries of Jacob D. Epp, 1851-1880 (University of Toronto Press, 1991). 


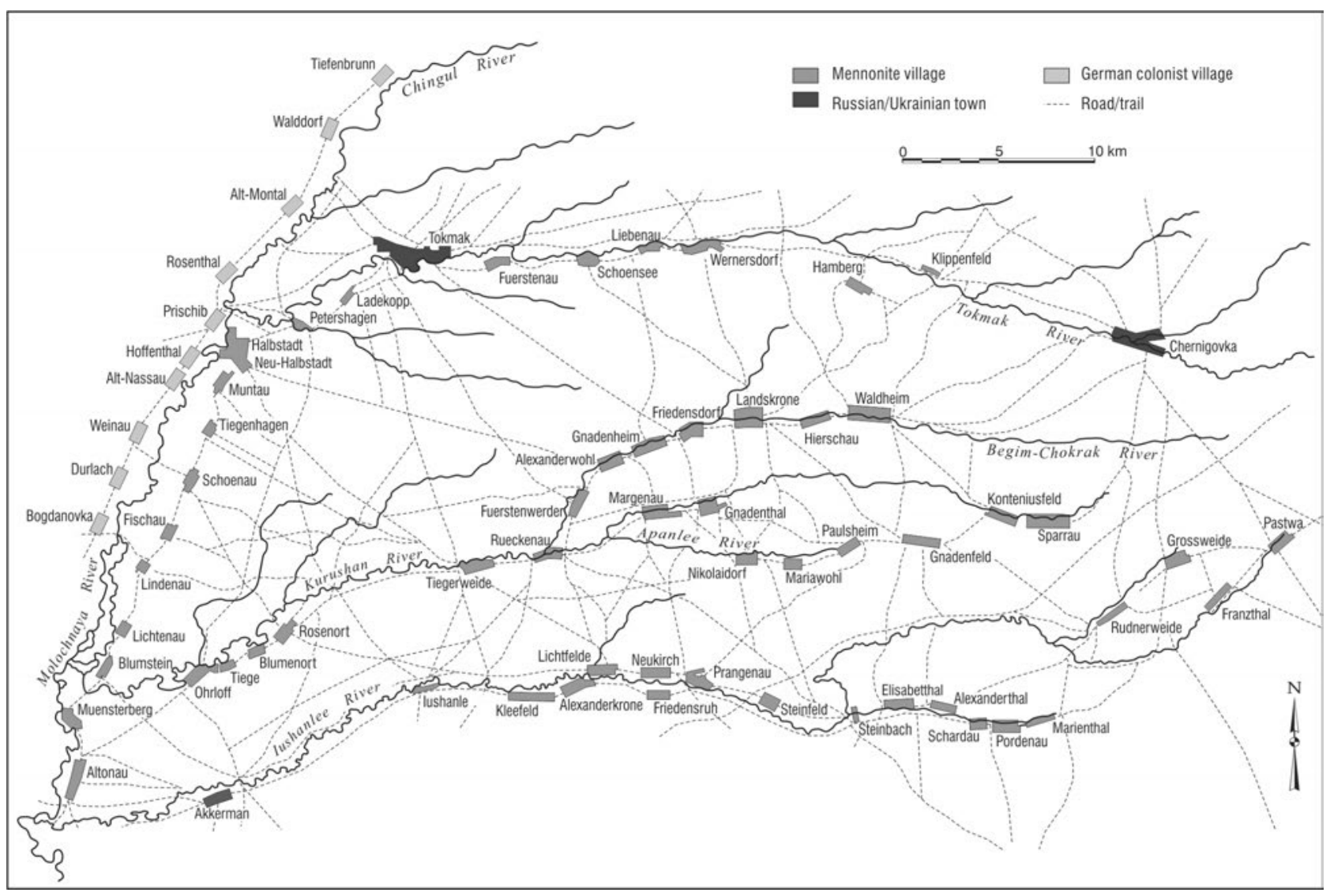

Map 2: The Molochnaia Mennonite Settlement. William Schroeder and Helmut Huebert, eds., Mennonite Historical Atlas, 2nd ed. (Springfield Publishers, 1996). Used with permission. 
This page intentionally left blank 